\title{
Functioning of the agro-industrial complex in the digital economy
}

\author{
Tatiana Medvedskaya ${ }^{1 *}$, Elena Zaporozceva ${ }^{1}$, Natalia Zemlyakova ${ }^{1}$, and Oksana Yuryeva ${ }^{1}$ \\ ${ }^{1}$ Don State Technical University, 1, Gagarina sq., 344003, Rostov-on-Don, Rostov Region, Russia
}

\begin{abstract}
Digital solutions are increasingly infiltrating all segments of agriculture. To achieve profitability growth, agribusiness is extremely important to maximize the use of innovative technologies. Today is the time when intelligent digital solutions should help the agricultural industry cope with the problems of increasing productivity and sustainable development. In the article, the author considers the peculiarities of the functioning of the agro-industrial complex in the digital economy, within the framework of the article the Largest participants in the agro-industrial complex market, who combined efforts to digitalize agriculture, were considered. It was established that agro-industrial enterprises are mainly digitalized at their own expense, which is a consequence of the "lack" of support tools, and the result is an insufficient level of implementation of technologies and platform solutions in the agro-industrial complex as a whole. The factors that restrain the digitalization of the agro-industrial complex today are financing, infrastructure, and personnel. At the same time, there are a lot of federal support measures, it is necessary to analyze them again, first of all, at the regional level, and understand why they are not so actively used by entrepreneurs, SMEs, and, if necessary, form proposals for adjustment together with the business and expert community.
\end{abstract}

\section{Introduction}

Currently, all sectors of the economy have undergone digital transformation, and the agroindustrial complex has not been an exception. However, the introduction of digital technologies that increase the level of informatization and automation has mixed consequences: on the one hand, simplifying the relationship of agricultural producers with the state, improving quality and reducing losses, and on the other, potential unemployment caused by the introduction of smart technologies.

By Decree of the President of Russia of 07.05.2018 No. 204 "On National Goals and Strategic Objectives for the Development of the Russian Federation for the Period until 2024 ," the task of transforming priority sectors of the economy and social sphere, including agriculture, through the introduction of digital technologies and platform solutions was set [1].

* Corresponding author: medvedskaya72@mail.ru 
The relevance of the proposed study theme is that in the context of a pandemic, it is COVID-19 necessary to find new ways to develop the sphere of AIC, which involves studying modern concepts and ideas.

Modern agrarian transformations help increase the production capacity of the industry, providing the country with food security. However, this requires a constant search for not only financial resources to update not only the material and technical side of the production process, but also to attract labor resources. At the same time, qualified personnel will be the key driving force in the activation of innovative processes for the formation and implementation of strategic directions in the agricultural sector. The need for continuous and continuous renewal of labor potential is due to scientific and technological progress, accompanied by the constant introduction of resource-saving technologies, new highperformance equipment and more efficient forms of organization of labor processes. This becomes most relevant in the conditions of digitalization of agriculture, when there is a need to attract and consolidate young highly qualified specialists with special training who have received education in the field of economics in working with digital technologies.

Accordingly, the topic is of applied importance, as it will make it possible to understand the reasons why the use of digitalization tools is justified for agro-industrial complexes in the regions, and Russia as a whole in the context of an increase in the share of consumers saving on costs.

The domestic digital technology market in the agro-industrial complex is already estimated at 360 billion rubles, and by 2026 it should grow five times. For this, the state will focus on three key areas in the development of digitalization of the agricultural sector.

\section{Materials and methods}

As the main methods of research, analysis and synthesis were used, which made it possible to assess the current state of use of the labor potential of the region and identify the main directions in solving issues of personnel support of the industry. Economic and statistical analysis was used.

\section{Results and discussion}

The population of the land has grown more than 3 times over the past 70 years. Agroindustry and agriculture do not keep pace with the growing need. Agriculture is becoming a very data-intensive sector. The introduction of new technologies, Big Data and the Internet of Things in agriculture can turn an industry less affected by IT into a high-tech business due to high productivity growth and reduced overhead.

In terms of digitalization, Russia is in 15th place among the countries of the world. In recent years, domestic farmers have adopted machine vision, motion autonomy, artificial intelligence, big data analysis technologies, and began to more actively purchase innovative machines. At the same time, the share of agricultural enterprises covered by digitalization in the Russian Federation remains quite low (7-10\% against 69\% in Europe).

The concept of "Digital Economy" is enshrined in the Strategy for the Development of the Information Community in the Russian Federation for 2017-2030, approved by Decree of the President of the Russian Federation dated 09.05.2017 No. 203 [2]. Agriculture, being an integral part of the agro-industrial complex, is forced to rapidly become high-tech and innovative, allowing to measure in detail all processes taking place on land or farm [3]. [1].

The stages of digitalization of the agro-industrial complex can be reflected as follows 
Table 1. Stages of digitalization of agro-industrial complex.

\begin{tabular}{|l|l|l|}
\hline Stage Period & Stage Name & Stage Characteristics \\
\hline $1967-1980$ & Automation & $\begin{array}{l}\text { Creation of automated process control and monitoring systems } \\
\text { with low power and large size }\end{array}$ \\
\hline $\begin{array}{l}1990 \text { beginning } \\
\text { of the 2000th }\end{array}$ & Electronization & $\begin{array}{l}\text { Introduction of computers and electronic sensors into } \\
\text { agricultural production }\end{array}$ \\
\hline Present stage & Digitalization & $\begin{array}{l}\text { The use of more modern computers and the use of the } \\
\text { information potential of the Internet. Start using accounting } \\
\text { programs. Start of creation of state information systems }\end{array}$ \\
\hline
\end{tabular}

Speaking about digitalization of agriculture, it should be noted that this industry has a number of specific features in which digital technologies could find their application, among them it is possible to distinguish [3]:

- The field of life of living organisms, plants and animals, in which advanced technological equipment could be widely used in order to control and manage agricultural facilities and minimize human errors in this area;

- reducing the complexity of production processes for the employee using digital technologies;

- possibility of controlling and covering IT technologies of large territories;

- Variety of crops to take advantage of technological advances.

Digitalization of agriculture is also necessary in order to solve a number of problematic issues, because of which Russia is inferior to world leaders in this area of activity. To this end, special attention should be paid to increasing the quantity and quality of crops; reducing the labor intensity of agricultural processes, and, therefore, reducing the human factor for the level of yield; minimizing investments that significantly frighten representatives of the business sector who are in search of an area of activity. It is impossible to note that when introducing new technologies, special emphasis should be placed on their safety for humans and the environment.

The main tasks that need to be solved for the digital transformation of the industry:

- Improving the effectiveness of state support measures by reducing costs and time frames when providing state support, developing relevant areas of state support that stimulate the growth of sales of agro-industrial products;

- Encouraging the introduction of digital technologies into the production processes of agro-industrial enterprises, including through state support;

- Increasing the efficiency of inter-economic interaction of enterprises of the agroindustrial complex and interaction with the state;

- Improving management efficiency in the agro-industrial complex through the introduction of end-to-end digital technologies;

- Creation of technologies for obtaining, verifying, structuring, synthesizing and analysing reliable and relevant data on the state of the agro-industrial complex, necessary for making sound and timely management decisions;

- Creation of technologies and services that facilitate access of agro-industrial enterprises to credit and insurance products;

- implementation of the principles of a unified system of identification and authentication, maintaining the digital profile of enterprises of the agro-industrial complex.

According to the ministry, the Russian digital technology market in the agricultural sector today is about 360 billion rubles and by 2026 should grow five times [4]. Regional information systems, including information on the status and use of agricultural land, are an important part of State monitoring of such land. Information systems for monitoring the 
state and use of agricultural land successfully functioned in 22 regions of Russia: the republics of Mordovia, Tatarstan, Sakha (Yakutia), Buryatia; Krasnodar, Stavropol and Altai Territories; Belgorod, Kaluga, Kursk, Lipetsk, Moscow, Oryol, Tambov, Yaroslavl, Kaliningrad, Volgograd, Samara, Saratov, Kurgan, Irkutsk, Novosibirsk regions. A number of Russian software development organizations participate in the creation of regional agricultural land monitoring systems [4]. Of these, the most widely distributed software products of the following companies:

- OOO "A Program System" - information systems in Belgorod,

- Bryansk, Lipetsk, Oryol, Tambov, Saratov, Tomsk regions,

- the republics of Mordovia, Sakha (Yakutia), Primorsky region;

- DATUM Group - in Kurgan, Rostov regions;

- Information and analytical consulting systems LLC - in the Krasnodar, Stavropol Territories, Volgograd, Tyumen regions;

- PJSC Rostelecom - in the Altai Republic, Altai region.

Tools and data of a kosmomonitoring are used also for registration of receiving subsidies from the federal budget for contracts of agroinsurance with state support [4].

Each global company of the market of agrarian and industrial complex applies digital solutions practically on all chain of creation of a product, on all management processes now. "In Russia - it isn't so developed now, we see rather single examples now. Pioneers are Miratorg and Cherkizovo here.

So, use of digital technologies in management of agro-industrial complex is characterized by active use in the agricultural industries of specialized databases and the software. The Clever technology land use assumes certain types separation of all lands (field, economy, municipality, the territorial subject of the Russian Federation, belongings to the country) [6] and according to them implementation of digital planning and modeling by means of geoinformation technologies (for example, GPS). The Clever system the field possesses analytical data on a condition of soils, the environment and the planted plants with further application of collecting and cultivation of such plants by means of digital technologies.

The "clever" garden is a uniform system in which all data on the areas occupied with industrial gardens a condition of the soil for carrying out monitoring of activity of such plants and in need of acceptance of all measures for her improvement are collected.

The following innovation - information Clever technology the greenhouse which marks work on the whole robotic complex occupying rather small territory provided with a control system of a microclimate, lighting, energy saving, food and autonomy for the purpose of the systematic growth of quality of the grown-up products.

The technological Clever complex a farm has a direct bearing on branch of domestic livestock production (in particular cattle), to increase in efficiency of animals, decrease in level of diseases, active application of an autonomous system on farms, to control of safety and quality of a bed product.

It should be noted the relevant direction of through technologies and formation of research competences which consists in cooperation the Ministry of Agriculture of the Russian Federation with the Ministry of Science and Technology of Russia and involvement of young qualified specialists to developments of information projects in the field of through technologies, the Internet of things, robotics and remote technologies further having broad application in agriculture for the purpose of his fastest digitalization $[1]$.

In the Rostov region there is a process by process of creation of the Southern scientific education center "Digital Transformation of Agro-industrial and Industrial Complex" [6]. According to Rostovstat, in 2020 in the Rostov region 1,096.7 thousand tons of raw milk were produced (as well as in 2019), the average yield of milk from one cow made 4,845 kg 
(1.3\% more, than the previous year). To increase the raw materials output for ensuring need of local producers of dairy products, in 2021 in the Don region it is planned to construct two livestock complexes of the dairy direction. One of them - the Zhukovsky complex which will be constructed in Peschanokopsky district and, as expected, will be put into operation in December, 2023. An initiator of the project is the joint-stock company firm "Agricultural complex of N.I. Tkachyov", the total amount of financing is 3.4 billion rubles. It is supposed that in a year after commissioning on a complex 2,800 heads of the main herd will already contain and an object will reach design capacity of production of $25,200 \mathrm{t}$ of milk a year. The complex will be equipped with the modern equipment with the automated control system that will allow to receive milk of ideal quality for production of cheeses. The dairy farm will work by the principle of the closed cycle: cultivation of young growth and all productions will happen on one platform.

The second dairy complex is planned to be created in the Salsk district. An investor of the project is JSC Agricultural Holding Step, the volume of investment will be 2.1 billion rubles. An object is also planned to be put into operation in December, 2023, and in December of the 2024th it has to reach design capacity. The complex will be calculated on the content of 3.1 thousand fodder cows, the general livestock can reach 7 thousand cows. Will grow up heifers there, to produce raw milk and beef in live weight.

In the Rostov region, vegetable growing, in particular cultivation of hothouse vegetables is also developed. According to Rostovstat, last year the production of vegetables of the protected soil in the region was 62,420.4 that practically corresponds to the level of 2019 $(62,416.3 \mathrm{t})$. To increase security of consumers with vegetables in off-season, in 2021 in the region construction of two hothouse complexes will begin.

The first project is implemented by LLC UK ROST: it provides construction of the third stage of a hothouse complex with utilities for year-round cultivation of vegetables which has to be put into operation in December, 2021. The company plans to increase the area of greenhouses by $46.1 \%$ and to bring them to 21.91 hectares. The total amount of financing of the third stage of the project is 1.7 billion rubles.

The second project - construction of a hothouse complex with a total area of 11.7 hectares for cultivation of vegetables and green cultures. An investor is LLC PMT, in implementation of the project is planned to invest 1.9 billion rubles. It is expected that in December, 2022 the complex will be put into operation, and in December of the 2023rd will reach design capacity for year-round production of 7 thousand tons of products a year.

Implementation of such large investment projects will allow to solve a problem of security of need of residents of the Rostov region for milk and dairy products, beef and also hothouse vegetables of own production at the affordable prices. Besides, opening of large production sites will allow to create additional jobs in the village [8].

However these decisions are still insufficiently integrated among themselves and with the state systems. It does crucial a role of the state in creation of the open platform capable to unite services for the farmer of the state and also development of digital platforms and ecosystems at the initiative of government institutions (first of all, the Ministry of Agriculture of the Russian Federation) [10].

Innovative technologies of processing and logistics will help to save on fuel, storage, packing and transportation of products from 10 to $40 \%$. The production efficiency can be increased significantly by means of the new systems of agriculture. For example, city farms of vertical type (first of all greenhouses) can be developed in not used squares - attics or basements. In turn, platforms of electronic commerce for agrarian and industrial complex allow to exclude from a supply chain of intermediaries - the farmer can interact on the electronic platform directly with the client.

\section{Discussion}


Currently, almost all rural producers understand that the use of digital technologies is the main condition for survival in the market [2]. Digitalization of agriculture, first of all, will affect accounting specialists

- it is intended to modify the business information support system, in which the role and importance of accounting and financial reporting are undeniable [5]. Financial reporting is an important and peculiar thread that allows us to link the various information needs of economic actors in the market. It is the financial statements that are now recognized by most users as the main source of information due to the following factors:

- The totals of the financial statements are based on the primary accounting documents and ledgers so that they can be checked and monitored;

- The data in the financial statements are systematized according to common accounting rules and principles for all entities, thus ensuring comparability of reporting data and conducting dynamic analysis of indicators;

- tightening of market competition and orientation towards the digitalization of the economy require economic entities to create an official website and ensure the publicity of business activities, which allows interested users to access the financial information of the enterprise;

- The financial statements of individual economic entities are subject to external control by audit organizations, tax firms, banking and state structures, which determines its fair and responsible formation.

As drivers of the development of the digital transformation of the agro-industrial complex in Russia, experts note the high degree of cooperation of digital service providers for this complex and the practical lack of competition; the availability of large agricultural holdings; state measures for the development of the digital economy. Agricultural producers expect that modern digital technologies will help them in solving pressing economic issues and problems, among the main ones of which they include:

- Low profitability not sufficient for efficient production development;

- The need to take into account and prevent the risks of agricultural production: weather, plant and animal diseases, pests, prices for products in the season, prices for fuel and lubricants and others;

- difficulties with access to competencies of qualified specialists;

- Significant cost of own time for planning and control of execution "in the field" to the detriment of other production and management tasks;

- unproductive resource losses (fertilizer, GSM, NWR, etc.);

- Difficulties in accessing advanced technologies, practices and knowledge bases;

- The need to simplify work with the State (taxes, reporting, checks);

- difficult access to finance and insurance.

In addition to financial issues, there are also infrastructure issues that deter the introduction of digital technologies in agriculture. Despite the fact that according to the results of studies, the average digitalization score of regions is 6.4 , many traditionally agricultural regions are below the average score

In addition to the main problems that complicate the digital transformation of agriculture in Russia by farmers as consumers of digital products, developers of specialized programs and systems call the following barriers to the development of the industry:

- low industry margin (developing segment) - unattractive for technological and infrastructure investor;

- Disadvantageous adaptation of proposed solutions for small and medium-sized households;

- A small amount of open, regular business data that developers can use to create applications and services; underdevelopment of "paperless" government services and services required in agribusiness; 
- Lack of awareness of agribusiness both about the existence of the technologies themselves and about the results of their use in real farms;

- Complexity of integration of digital technologies with all other business processes in the enterprise;

- Absence of ready-made integrated 48 digital solutions on the market, hence the need for additional integration of individual digital instruments into a single system;

- The need for significant costs for the creation of a national digital infrastructure, as well as the formation of a specialized information system in each subject of the federation, its integration into other information bases.

Thus, the main "application points" of digital technologies in the agri-food industry can be: increasing production efficiency (crop yields and animal productivity); reduction of production costs, increase of labor productivity; timely response to climate change; Reduce transaction costs in sales by building a transparent field-to-consumer supply chain; minimizing management risks; reducing the shortage of skilled labour; timely provision of important information to rural producers; easier access to borrowed funds; obtaining access of agricultural producers to digital distribution channels.

In monetary terms, the market for information technologies in agriculture is estimated at more than 360 billion rubles. According to forecasts of the Ministry of Agriculture, it should grow 3-5 times in the next 10-15 years [11]. According to the federal agricultural department, the comprehensive digitalization of agricultural production will allow farmers to reduce costs by $23 \%$, reduce crop losses, which with the inefficient use of production means can be up to $40 \%$. Processes in agricultural holdings are more complicated, and the effect of transformation is much greater. For example, in basic automation, it is one thing when a large farm buys agricultural machinery for efficient land cultivation, while for small farms this is often excessive and inefficient. But the fundamental difference between digitalization is that the results of the use of digital technologies can scale, and over time they will become more accessible.

Thus, today in the agro-industrial complex there are successful practices not only in the implementation of various solutions, but also successful practices in general digitalization of enterprises. In addition, the technologies used in the agro-industrial complex are not only competitive in the Russian and international markets, but there are solutions that have no analogues in the world.

\section{Conclusion}

An analysis of the country's agricultural industry made it possible to conclude that modern agriculture is unthinkable without digital technologies. Digitalization is the future, without it there is no way forward. Artificial intelligence analyzes information and makes recommendations on the basis of which decisions can be made. This makes it possible to significantly reduce risks and increase the economic efficiency of agriculture.

Among the problems of digitalization of the agro-industrial complex, such as the shortage of personnel, the outflow of young specialists from villages, lack of confidence in the justification of costs, low digital literacy and conservatism, sabotage of the introduction of automation systems, ensuring transparency of processes, legislative barriers in the field of certification and operation of technologies are highlighted.

Summing up all this, I would like to note that the contribution of the agricultural sector to the digitalization of the economy of our country as a whole depends on the competent implementation of all requirements, as well as the directions presented. At the moment, some steps have already been taken to implement the goals set, which are expressed in the creation of the interdepartmental project "Digital Agriculture." In our opinion, this project 
will soon show its effectiveness, reducing unnecessary costs and contributing to the maximization of the profitable part of agricultural production.

\section{References:}

1. A.V. Mikhailova, T.K. Medvedskaya, S.V. Laptev, O.A. Dvoryankin, V.E. Rubanik, Academy of Entrepreneurship Journal, 25 (Special Issue 2), (2019)

2. V. Tkach, E. Medyukha, N. Zemlyakova, L. Pudeyan, K. Chanturia, E. Moskvitin, IOP Conference Series: Earth and Environmental Science. 12th International Scientific Conference on Agricultural Machinery Industry, INTERAGROMASH (2019) doi:10.1088/1755-1315/403/1/012134

3. J.C. Dos Reis, R. Bonacin, A. Correa, K.R.E. Jesus, O.F.N.A. Araujo, Proceedings 2018 IEEE 27th International Conference on Inclusion Technologies: Infrastructure for Shared Enterprises, WETICE 2018, 8495950 (2018)

4. N. Muntali, K. Leuwis, A.Van Paassen, R. Van Lammeren, M. Schut, NJAS Wageningen Journal of Life Sciences, 86-87, (2018)

5. M.V. Gestrin, J. Staudt, The digital economy, multinational enterprises and international investment policy, Paris (2018)

6. J.C. Guillermo, A. García-Cedeño, D. Rivas-Lalaleo, M. Huerta, R. Clotet, Advances in Intelligent Systems and Computing, 893 (2019)

7. A.V. Shokhnekh, N.N. Skiter, A.F. Rogachev, T.V. Pleschenko, E.V. Melikhova, Journal of Advanced Research in Law and Economics, 7, (2016).

8. L.G. Matveeva, A.Y. Nikitaeva, O.A. Chernova, Terra Economicus, 16 (1), (2018)

9. N.A Kosolapova, L.G. Matveeva, A.Y. Nikitaeva, L. Molapisi, Journal of Hydrology, 553 (2017)

10. T.V. Kushnarenko, O.A. Chernova, L.G. Matveeva, Economy of Region, 12 (3) (2016)

11. T. Kuchnarenko, L. Pudeiyan, E3S Web Conf. 175, 2020, XIII International Scientific and Practical Conference «State and Prospects for the Development of AgribusinessINTERAGROMASH 2020», 29 June 2020, (2020) doi: $10.1051 / \mathrm{e} 3 \mathrm{sconf} / 202017513021$

12. T. Kushnarenko, P.Shumilin, O.Yuryeva, T. Medvedskaya, E. Zaporozceva, E3S Web of Conferences, 164, 06037 (2020) doi: 10.1051/e3sconf/20201640603711

13. L.G. Matveeva, E.V. Mihalkina, O.A. Chernova, A.Ju.Nikitaeva, Journal of Applied Economic Sciences, 10 (7) (2015)

14. V. Mau, The Russian economy in 2017. Trends of Perspective, (Moscow: Publishing house of the Gaidar Institute) ed S Sinelnikova-Muryleva (2018)

15. V.G. Zakshevsky, O.G. Charykova, I.N. Merenkova, Strategic Priorities For Developing The Agro-Industrial Complex And Rural Areas Of The Region, IOP Conference Series: Earth and Environmental Science (2019)

16. E. Bornhofen, T. Ramires, T. Bergonci, L. Nakamura, A. Righto, Agricultural Systems, 173 (2019) 